\title{
Research on Overflow Monitoring Mechanism Based on Downhole Microflow Detection
}

\author{
Liang Ge, ${ }^{1,2}$ Ze Hu, ${ }^{3}$ Ping Chen, ${ }^{4}$ Lei Shi, ${ }^{4}$ Qing Yang, ${ }^{1}$ and Junbi Liao ${ }^{2}$ \\ ${ }^{1}$ College of Mechanical and Electronic Engineering, Southwest Petroleum University, Chengdu 610500, China \\ ${ }^{2}$ Department of Measuring and Control, Sichuan University, Chengdu 610065, China \\ ${ }^{3}$ College of Electric and Information, Southwest Petroleum University, Chengdu 610500, China \\ ${ }^{4}$ State Key Laboratory of Oil \& Gas Geology and Exploration, Chengdu 610500, China \\ Correspondence should be addressed to Liang Ge; cgroad@swpu.edu.cn
}

Received 19 October 2014; Revised 12 November 2014; Accepted 18 November 2014; Published 16 December 2014

Academic Editor: Marek Lefik

Copyright (c) 2014 Liang Ge et al. This is an open access article distributed under the Creative Commons Attribution License, which permits unrestricted use, distribution, and reproduction in any medium, provided the original work is properly cited.

\begin{abstract}
The flow rate variation of the drilling fluid and micro-overflow loss is difficult to analyze. The purpose to prevent the occurrence of kick, lost circulation, and other complex conditions is not easy to be achieved. Therefore, the microflow-induced annulus multiphase flow rate and annulus pressure field model were studied, and a downhole microflow measurement system has been developed. A differential pressure type flow measurement was used in the system, and real-time downhole information was obtained to achieve deep, narrow windows and other safety-density complex formation security. This paper introduced a new bottom-hole flow meter which can measure the annular flux while drilling and monitor overflow and circulation loss. The accuracy and reliability of the MPD (managed pressure drilling) system can be improved obviously by applying the device; as a result, the safety of drilling is enhanced and the cost is reduced.
\end{abstract}

\section{Introduction}

Along with the rising of total demand of oil and gas resources, the explosion and development of world oil and gas is stepping into the peak gradually [1]. Drilling engineering has become the focus of the oil and gas exploration and development. For the drilling operation is a hidden underground engineering, which has a large scale, high investments, and high risk, there is a lot of randomness, fuzziness, and uncertainty. Because of the misunderstandings of the objective situation or the errors in decision-making of the subjective consciousness, it may cause plenty of complex situations and serious disaster. The blowout accident is one of the most common and heavy loss safety accidents [2]. Overflow is the precursor of blowout, which is caused by the unbalance formation pressure of the bottom hole during the drilling process. In the drilling process, overflow will invade the well due to various reasons, which will cause fluid contamination and drilling corrosion without timely detection.

Timely and early detection of overflow can prevent blowout accidents, reduce equipment damage caused by blowout, protect personnel and oil and gas resources, reduce environmental pollution, and ensure safe drilling, which plays an important role in the safe and effective development and the utilization of underground oil and gas resources [3].

Currently, to monitor the drilling operation, the mud level of the overflow tanks fixed on the ground is always detected. And then the formation fluid into the well of the overflow traffic can be determined from the mud level according to the principle of equal replacement [4]. However, this approach has two disadvantages: the first one is that when the formation fluid early invades wells; the excess flow is too small and difficult to be detected, which leads to a serious lag; the other one is that the type of overflow cannot be determined. Therefore, the existing detection methods cannot detect overflow accurately and reasonable plan cannot be made [5]. By monitoring the downhole microflow, the wellhead back pressure can be controlled and mud density can be finely adjusted to prevent from kick [6] and well leak disasters. Then, under safe and fast drilling in the condition of deep narrow mud window can be achieved. Therefore, it has become a trend in modern well-control technology to explore 


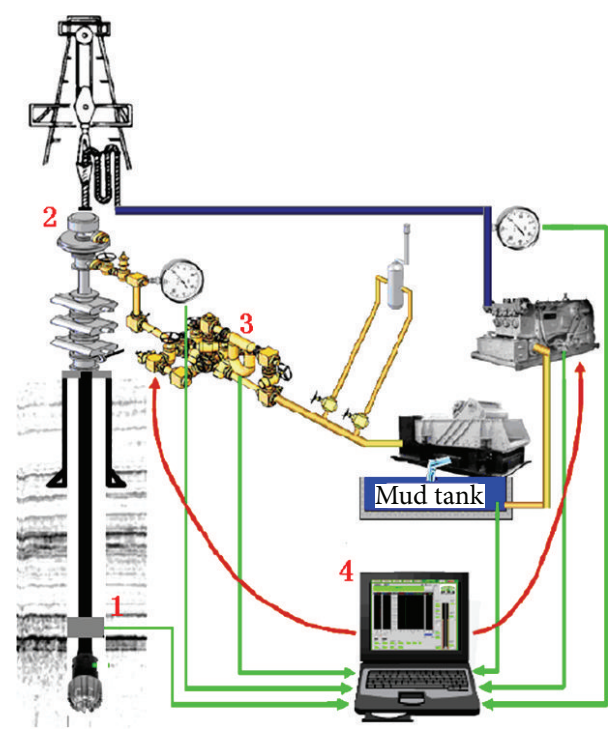

FIGURE 1: Block diagram of microflow control system. 1: downhole microflow detection system; 2: rotating blowout preventer; 3 : chokeline manifold; 4: ground control system.

and study new downhole overflow detection mechanisms and methods especially the technology of timely detection of overflow in the drilling process. This also ensures safe drilling and plays an important role in safe and effective utilization of oil and gas resources.

In order to measure the downhole annulus flow rate variation while drilling, a downhole annulus flow monitoring device must be designed. By measuring the annular flux while drilling and adjusting the open area of wellhead back pressure valve, the buttonhole pressure can be changed accordingly to control the overflow and lost circulation. This method can improve drilling safety and reliability and reduce drilling cost. The block diagram of microflow control system is shown in Figure 1.

\section{The Model of Downhole Microflow Detection System}

Based on the research on ultrasonic flow meter principle, electromagnetic flow meter principle, and differential pressure flow meter principle, differential pressure flow meter principle is used to realize the downhole microflow measuring [7]. The choke element is shown in Figure 2. Considering passing ability of mud carried cutting, the limitation of length and cross-sectional dimension, and the requirement of pressure differential, the choke element is designed based on the structure of the stabilizer.

(1) Calculate the choke element equivalent diameter of the annulus $\bar{d}$ :

$$
\bar{d}=\frac{4 A_{1}}{c_{1}} .
$$

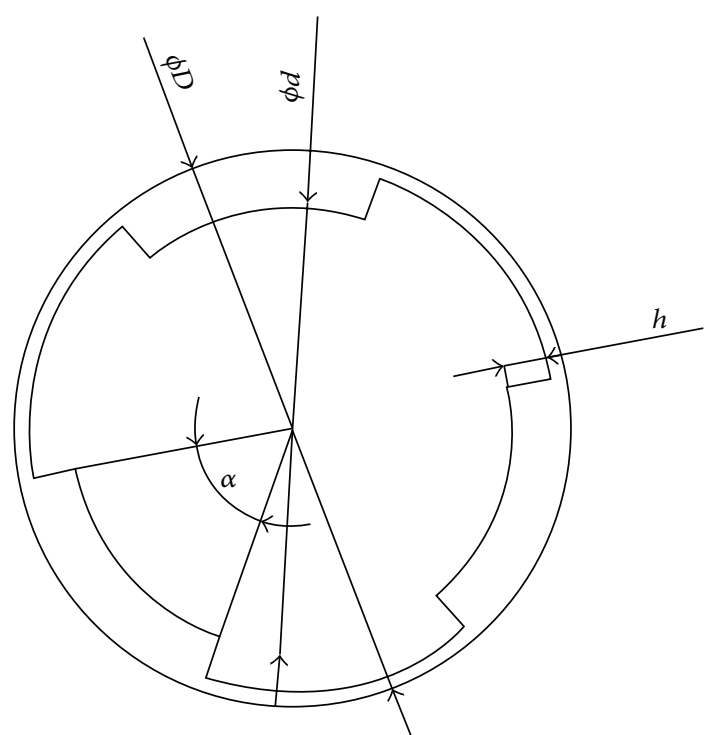

(a)

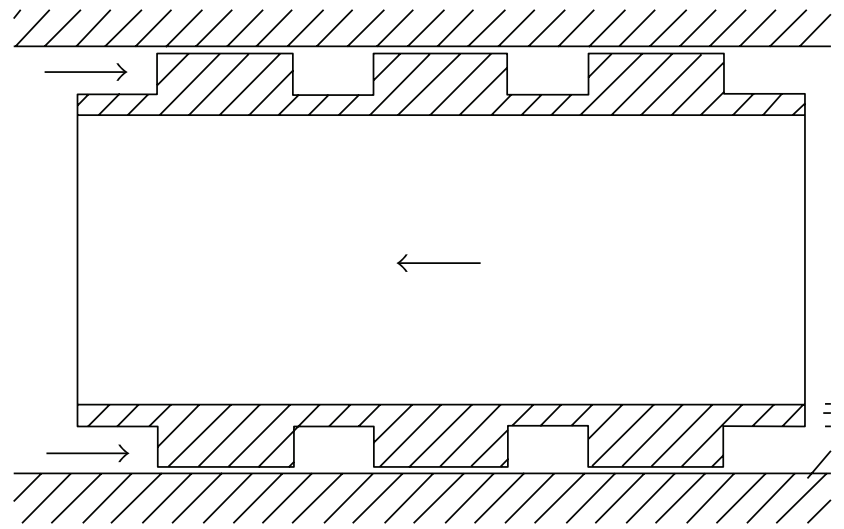

(b)

Figure 2: Schematic diagram of choke element.

$A_{1}$ is the annulus flow area of choke element, and

$$
A_{1}=\frac{\pi D o^{2}}{4}-\frac{\pi(d+2 h)^{2}}{4}+\frac{\alpha}{120}\left(\pi h d+\pi h^{2}\right) .
$$

$c_{1}$ is the wetted perimeter annulus of choke element, and

$$
c=\pi D o+\pi(d+2 h)\left(1-\frac{\alpha}{120}\right)+6 h+\pi d \frac{\alpha}{120} .
$$

The average annulus velocity of the choke element is

$$
v_{1}=\frac{Q}{A_{1}} .
$$

(2) Calculate the equivalent diameter between the drill pipe and the borehole annulus $\bar{d}^{\prime}$ :

$$
\bar{d}^{\prime}=\frac{4 A_{2}}{c_{2}} D-d d .
$$


$A_{2}$ is the cross-sectional area between drill pipe and wellbore annulus, and

$$
A_{2}=\frac{\pi\left(D^{2}-d d^{2}\right)}{4} .
$$
and

$c_{2}$ is wetted perimeter of drill pipe and wellbore annulus,

$$
c_{2}=\pi(D+d d) .
$$

The average velocity of the drill pipe annulus is

$$
v_{2}=\frac{Q}{A_{2}} .
$$

(3) The annulus fluid Reynolds number of the choke element is

$$
\operatorname{Re}=\frac{\bar{d} \cdot \rho \cdot v_{1}}{\eta_{p}\left(1+\left(\tau_{0} \cdot \bar{d}\right) /\left(8 \eta_{p} \cdot v_{1}\right)\right)} .
$$

For the structure stream $\lambda=96 /$ Re.

For the turbulent flow $\lambda=0.015 \sim 0.024$.

The frictional head loss of every choke element is

$$
h_{f 1}=\lambda \frac{\left(L_{1} / \cos \gamma\right)}{\bar{d}} \frac{v_{1}^{2}}{2 g} .
$$
is

Then the local head loss produced by each choke element

$$
h_{j}=\xi_{1} \cdot \frac{v_{1}^{2}}{2 g}+\xi_{2} \frac{v_{1}^{2}}{2 g}+\xi_{3} \frac{v_{1}^{2}}{2 g} .
$$

$\xi_{1}$ is the resistance coefficient sudden expansion of the local head loss, $\xi_{2}$ is the suddenly reduced drag coefficient of local head loss, and $\xi_{3}$ is flow resistance coefficient due to bending.

The differential pressure caused by each choke element is

$$
\Delta p=\rho g\left(h_{f 1}+h_{j}\right) .
$$

(4) The annulus fluid Reynolds number between the drill pipe and the borehole is

$$
\operatorname{Re}=\frac{\bar{d}^{\prime} \cdot \rho \cdot v_{2}}{\eta_{p}\left(1+\left(\tau_{0} \cdot \bar{d}^{\prime}\right) /\left(8 \eta_{p} \cdot v_{2}\right)\right)} .
$$

The frictional head loss between the drill pipe and wellbore annulus per unit length is defined by

$$
h_{f 2}=\lambda \frac{1}{\bar{d}^{\prime}} \frac{v_{2}^{2}}{2 g} .
$$

For the structure stream $\lambda=96 /$ Re.

For the turbulent flow $\lambda=0.015 \sim 0.024$.

(5) The pressure loss from the entrance point to the first stage chock is calculated by

$$
\Delta p_{1}=\rho g \frac{L-\left(n L_{1}+(n-1) L_{2}\right)}{2} \cdot h_{f 2}
$$

$\left(3 L_{1}+2 L_{2}\right)$ is the total length of 3 -grade chock.

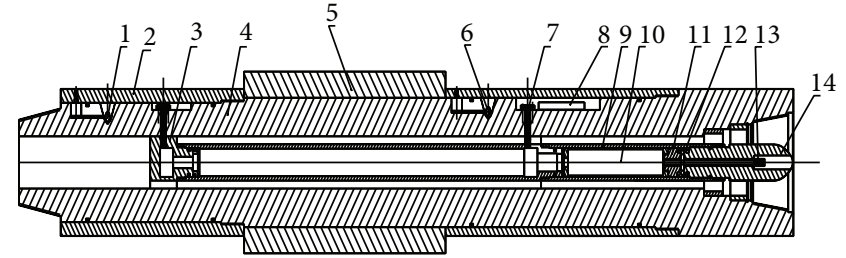

Figure 3: The structural drawing of bottom-hole flow meter. 1: pressure sensor, 2: protective casing, 3: the center tube plug, 4: main part, 5: choke element, 6: pressure sensor, 7: lead hole, 8: circuit board, 9: central tube, 10: battery, 11: electrical connectors, 12: hover connector, 13: multipin connector, 14: boot head.

is

The pressure loss before reaching the second stage chock

$$
\Delta p_{2}=\Delta p_{1}+\Delta p+\rho g \cdot L_{2} \cdot h_{f 2}
$$

The pressure loss before reaching the third stage chock is

$$
\Delta p_{3}=\Delta p_{1}+2 \cdot\left(\Delta p+\rho g \cdot L_{2} \cdot h_{f 2}\right)
$$
is

The pressure loss before reaching the fourth stage chock

$$
\Delta p_{4}=\Delta p_{1}+3 \cdot\left(\Delta p+\rho g \cdot L_{2} \cdot h_{f 2}\right)
$$

The pressure loss before reaching the $n$th stage chock is

$$
\Delta p_{n}=\Delta p_{1}+(n-1) \cdot\left(\Delta p+\rho g \cdot L_{2} \cdot h_{f 2}\right) .
$$

The pressure loss after arriving the $n$th outlet chock is

$$
\Delta p_{n+1}=\Delta p_{n}+\Delta p-0.3 \cdot \rho g \cdot \frac{\left(v_{1}-v_{2}\right)^{2}}{2 g}+\Delta p_{1}
$$

The measuring device is mounted near the drill bit, and the drilling fluid flows through the throttling element on which a differential pressure can be generated [8]. The differential pressure can be obtained by measuring the pressure of both ends of the chock element. The pressure is specified by annulus velocity of drilling fluid (or flow) as follows:

$$
\begin{aligned}
\Delta p & =p_{1}-p_{2}=\rho g\left(h_{f}+h_{j}\right) \\
& =\rho g\left(\lambda \frac{L}{d} \frac{\left(v_{1}(Q)\right)^{2}}{2 g}+\frac{\left(\left(v_{1}(Q)\right)^{2}-\left(v_{2}(Q)\right)^{2}\right)}{2 g}\right) .
\end{aligned}
$$

The structure diagram of the bottom-hole flow meter is shown in Figure 3.

In order to verify the correctness of the model [9], numerical simulations of the pressure distribution in the choke element are shown in Figure 4, which shows that the model fits both the calculation results and the experimental results [10]. 


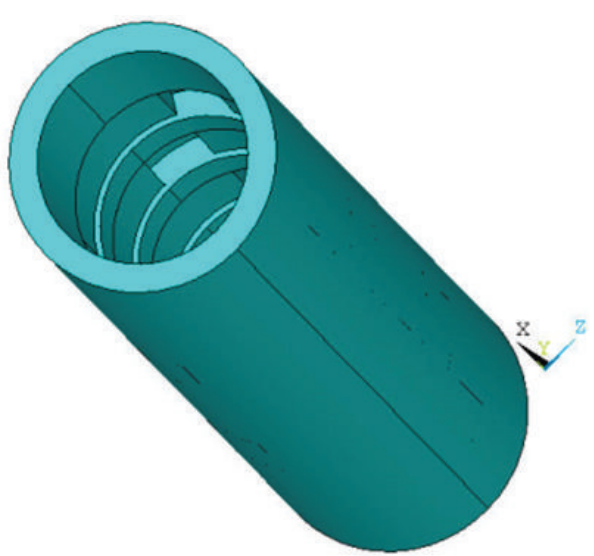

(a)
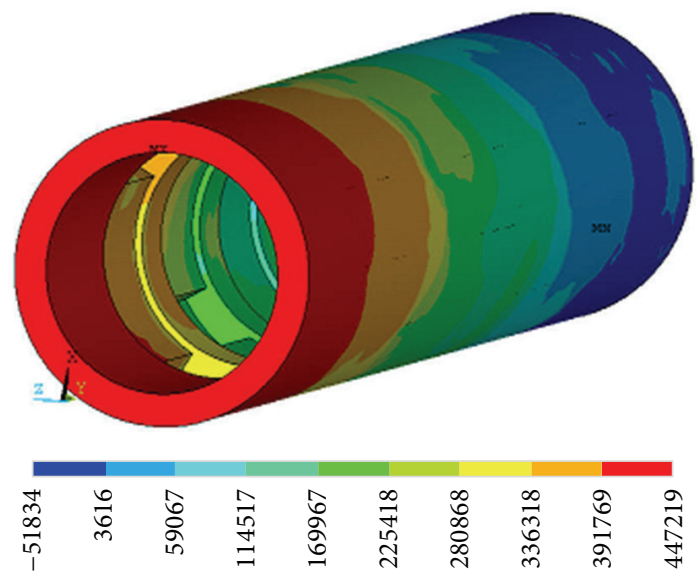

(b)

FIGURE 4: Numerical simulations of the pressure distribution in the choke element.

\section{Electrical System Design}

The downhole microflow detection system is considered as an intelligent system with high reliability of the downhole pressure acquisition, storage, transmission, and processing. Its main parts consist of circuit of MCU and PC [11]. The circuit of MCU can accomplish signal detection, signal conditioning, data acquisition, and storage of downhole pressure. PC parts mainly complete data analysis and processing functions; the circuit of MCU and PC parts are connected through MWD tools $[12,13]$. The two parts work together to accomplish the whole function of downhole microflow detection.

\section{Results and Discussions}

Applying bottom-hole flow meter in MPD can not only detect spills and leakage early but also take timely control measures. In order to verify the accuracy of the measurement instrument and the measurement result appropriate changes in the displacement of drilling fluid circulation are required, and the changes of the pressure values across throttling

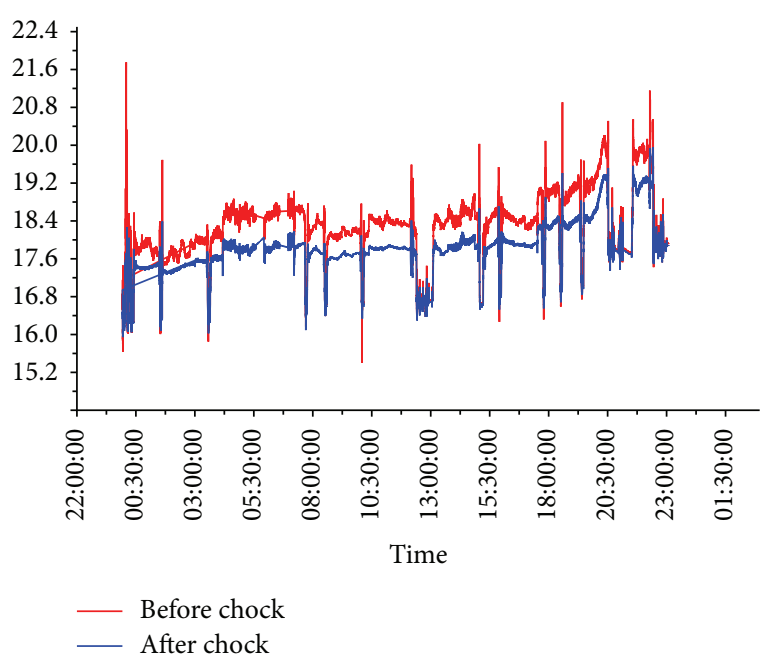

FIGURE 5: The spot data of pressure value before and after chock.

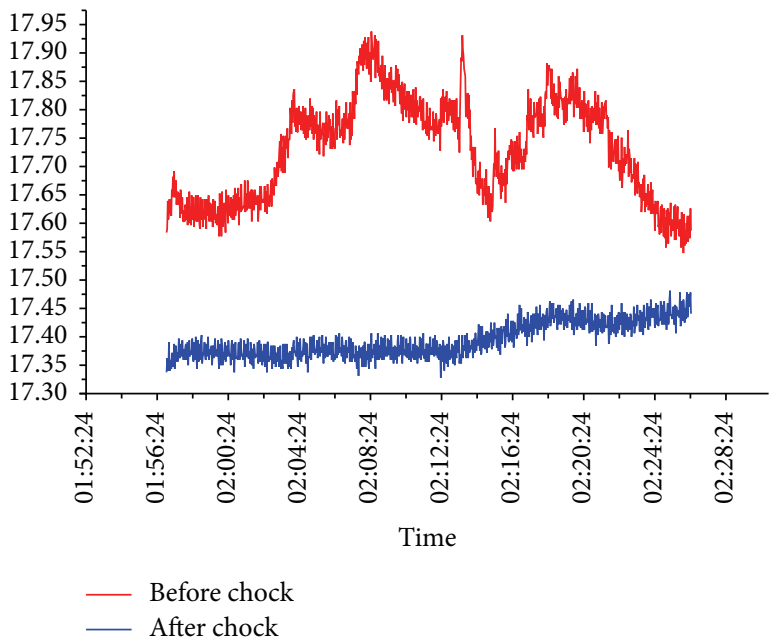

Figure 6: Pressure curve (single pump, pump stroke, 88 strokes/ $\min )$.

element are needed to be recorded. The spot data of pressure value before and after chock is shown in Figure 5.

The curve indicates that the test data of the downhole pressure basically meets the requirements of site conditions, the general trend of the annulus pressure measured by the instrument increases with the increase in depth, and a series of processes from drilling such as going down, drilling, redressing, and short trip can be reasonably reflected in the curve. Compared with the logging data, it can be seen that the three distinct steps in the curve are caused by adjusting the slurry density; the middle part in the curve and the two apparent pressure drops before drilling are due to short trip; a lot of glitches in the curve represent the root process orders. Due to a large amount of data, some of the pressure fluctuations on the curve cannot be distinguished. Segmental analysis is needed for further analysis.

As shown in Figures 6, 7, 8, 9, 10, and 11, the variation trend of the actual pressure curve which is similar to that of 


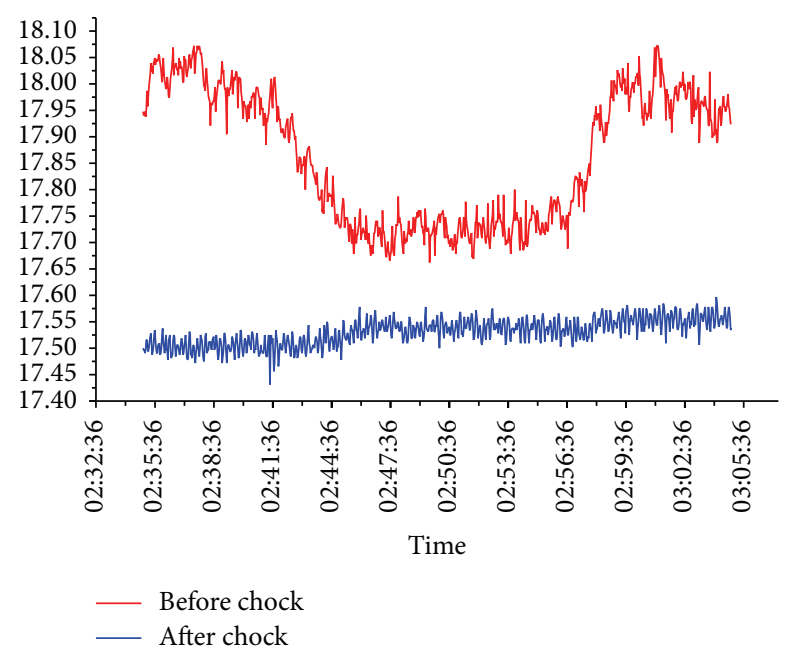

Figure 7: Pressure curve (single pump, pump stroke, 92 strokes/ $\min )$.

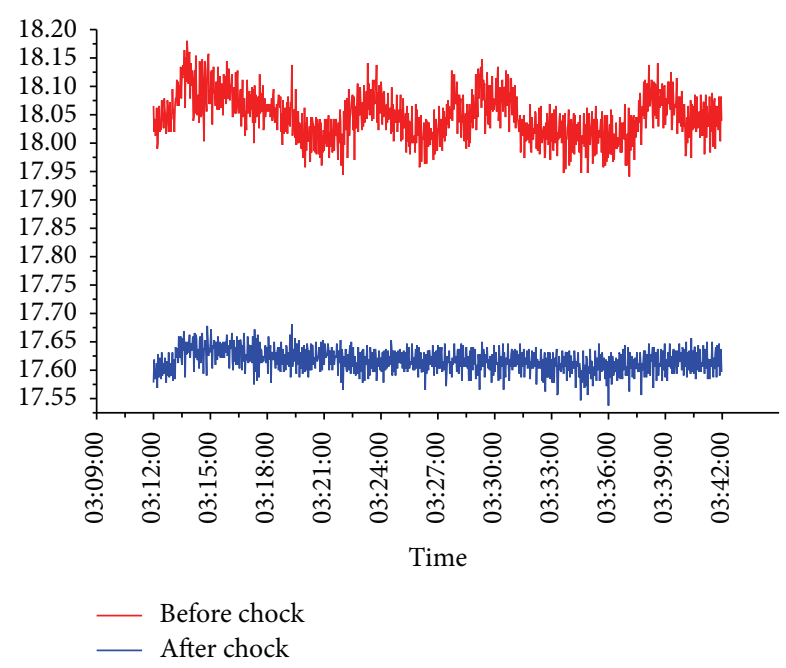

Figure 8: Pressure curve (single pump, pump stroke, 96 strokes/ $\min )$.

the theoretical pressure curve is increased with the increase of displacement. After data processing and operation, the relation table between the mud displacement and the differential pressure is established; and the relation table is shown in Table 1. However, there are some fluctuations in the actual pressure curve, which indicates that the downhole test environment is disturbed in some degree during the test.

\section{Conclusions}

As the development of drilling technique, a new technique called MPD has been developed on the basis of conventional drilling and UBD (under balance drilling) in the past few years [14-16]. This technique has been applied in some oil fields by now and good results have been obtained. However as a new technique, MPD still has some problems in theory

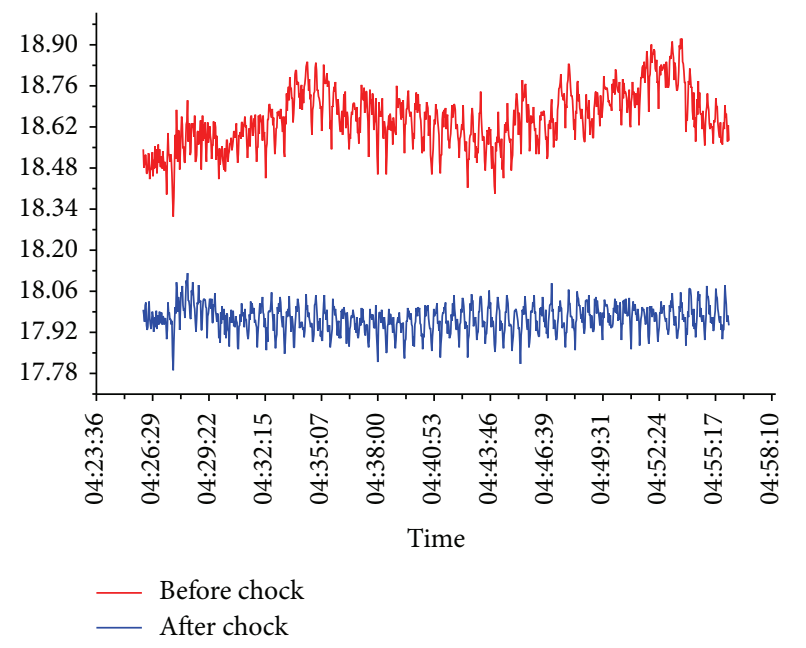

Figure 9: Pressure curve (double pump, pump stroke, 104 strokes/ $\min )$.

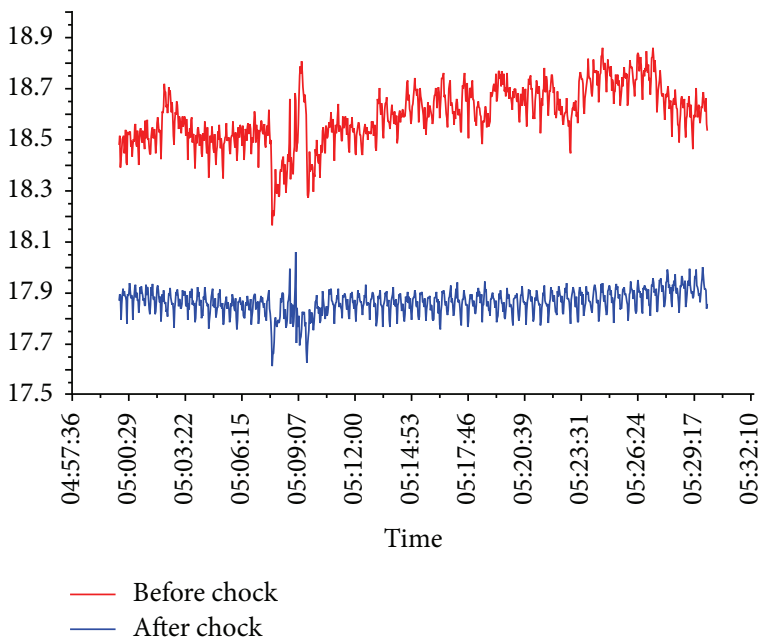

FIgURE 10: Pressure curve (double pump, pump stroke, 112 strokes/ $\min )$.

TABLE 1: The relation table between the mud displacement and the differential pressure.

\begin{tabular}{lc}
\hline Mud displacement $(\mathrm{L} / \mathrm{min})$ & Pressure difference $(\mathrm{MPa})$ \\
\hline 27.2 & 0.35 \\
27.54 & 0.39 \\
28.56 & 0.4 \\
28.9 & 0.43 \\
29.58 & 0.47 \\
33.32 & 0.59 \\
\hline
\end{tabular}

and hardware to be solved. The downhole microflow measuring device developed in this paper measures downhole annulus flow rate while drilling and early detects kick and well leak. The application of the device will greatly improve the current process of drilling well control capabilities, decrease 


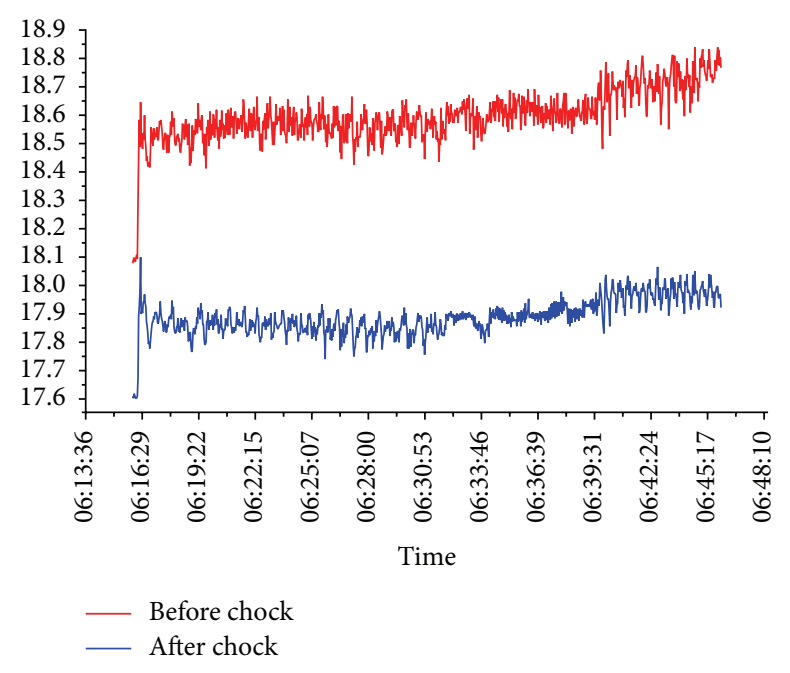

FIGURE 11: Pressure curve (double pump, pump stroke 116 strokes/ $\min )$.

the overflow and drain wells to a minimum extent, and reduce disaster risks.

\section{Conflict of Interests}

The authors declare that there is no conflict of interests regarding the publication of this paper.

\section{Acknowledgments}

This work is supported by Scientific Research Starting Project of SWPU (no. 2014QHZ029), National Natural Science Foundation of China (no. 21204139), and the State Administration of National Security (no. sichuan-009-2013AQ).

\section{References}

[1] H. M. Santos, K. J. Muir, P. Sonnemann, J. R. Kozicz, and C. Holt, "Optimizing and automating pressurized mud cap drilling with the micro-flux control method," in Proceedings of the SPE Asia Pacific Oil and Gas Conference and Exhibition, Perth, Australia, October 2008.

[2] P. Vieira, M. Arnone, I. Cook et al., "Constant bottomhole pressure: managed-pressure drilling technique applied in an exploratory well in Saudi Arabia," in Proceedings of the SPE/ IADC Managed Pressure Drilling and Underbalanced Operations Conference and Exhibition, SPE-113679-MS, Abu Dhabi, UAE, January 2010.

[3] J. C. Beltran, O. Gabaldon, G. Puerto-Corredor, V. Varon, and P. Alvarado, "Case studies-proactive managed pressure drilling and underbalanced drilling application in San Joaquin wells, Venezuela," in Proceedings of the SPE Annual Technical Conference and Exhibition, SPE-100927-MS, San Antonio, Tex, USA, September 2006.

[4] A. M. A. R. Shaikh, "3D managed-pressure drilling around a salt dome using coiled tubing: a case study-challenges and solutions," in Proceedings of the Abu Dhabi International Petroleum
Exhibition and Conference, SPE-102608-MS, Abu Dhabi, UAE, November 2006.

[5] H. Santos, P. Reid, and A. Lage, "Opening new exploration frontiers with the micro-flux control method," in Proceedings of the Offshore Technology Conference, OTC-16622-MS, Houston, Tex, USA, May 2004.

[6] R. Soto, J. Malavé, M. Medina, and C. Díaz, "Managed Pressure Drilling (MPD): planning a solution for San Joaquin field, Venezuela," in Proceedings of the IADC/SPE Drilling Conference, SPE-99116-MS, Miami, Fla, USA, February 2006.

[7] L. A. Carlsen, G. Nygaard, and M. Nikolaou, "Evaluation of control methods for drilling operations with unexpected gas influx," Journal of Process Control, vol. 23, no. 3, pp. 306-316, 2013.

[8] G. E. Liang, S. U. Fu, H. U. Ze, L. I. Qiang, and C. Rong, "Research on power line carrier technology for the intelligent drill pipe," Advances in Information Sciences and Service Sciences, vol. 5, no. 6, pp. 892-900, 2013.

[9] Y. Qing and D. R. Davies, "Generalized predictive control applied to intelligent production of an oil well," in Proceedings of the 6th IEEE Conference on Industrial Electronics and Applications (ICIEA '11), pp. 2033-2038, IEEE, Beijing, China, June 2011.

[10] L. Shi, P. Chen, Z. Hu, and Y.-J. Fu, "The application of bottomhole flow meter in the MPD system," Journal of Southwest Petroleum University, vol. 32, no. 6, pp. 89-92, 2010.

[11] G. E. Liang, H. U. Ze, Q. Yang, J. Li, and L. Xin, "Research on distributed optical fiber in oil well temperature field measurement system," Information Technology Journal, vol. 12, no. 18, pp. 4651-4654, 2013.

[12] D. P. Zhu and E. C. Yan, "Action mode of groundwater on landslide mass and standard variation curve of landslide stability when reservoir water rises," Disaster Advances, vol. 5, no. 4, pp. 721-725, 2012.

[13] S. A. Solvang, C. Leuchtenberg, I. C. Gil et al., "Managed Pressure Drilling Resolves Pressure Depletion Related Problems in the Development of the HPHT Kristin Field," SPE113672-MS, 2008.

[14] J. P. Schumacher, J. D. Dowell, L. R. Ribbeck, and J. C. Eggemeyer, "Subsea mudlift drilling: planning and preparation for the first Subsea field test of a full-scale dual gradient drilling system at Green Canyon 136, Gulf of Mexico," in Proceedings of the SPE Annual Technical Conference and Exhibition, SPE71358-MS, New Orleans, La, USA, September 2001.

[15] P. Fontana and G. Sjoberg, "Reeled pipe technology for deepwater drilling utilizing a dual gradient mud system," in Proceedings of the IADC/SPE Drilling Conference, SPE-59160-MS, New Orleans, La, USA, February 2000.

[16] A. Calderoni, G. Girola, M. Maestrami, H. Santos, and C. Holt, "Microflux control and E-CD continuous circulation valves allow operator to reach HPHT reservoirs for the first time," in Proceedings of the IADC/SPE Managed Pressure Drilling and Underbalanced Operations Conference and Exhibition, SPE 122270, San Antonio, Tex, USA, February 2009. 


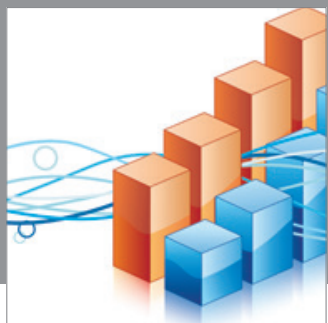

Advances in

Operations Research

mansans

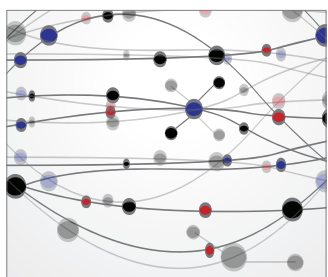

The Scientific World Journal
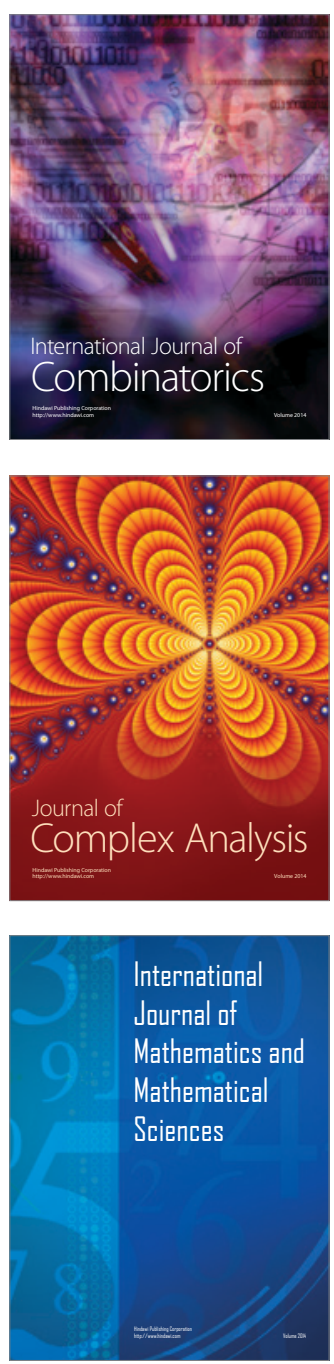
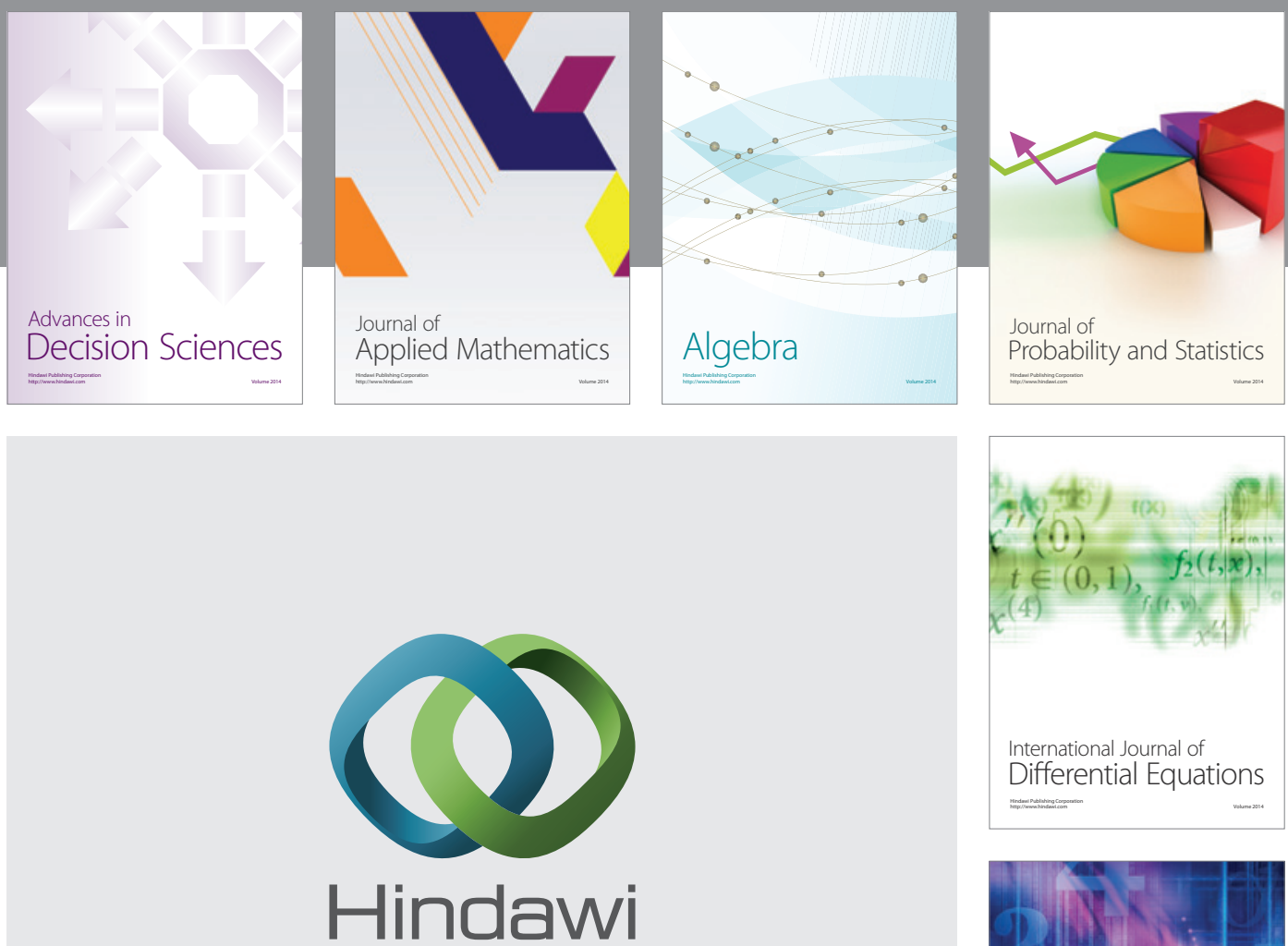

Submit your manuscripts at http://www.hindawi.com
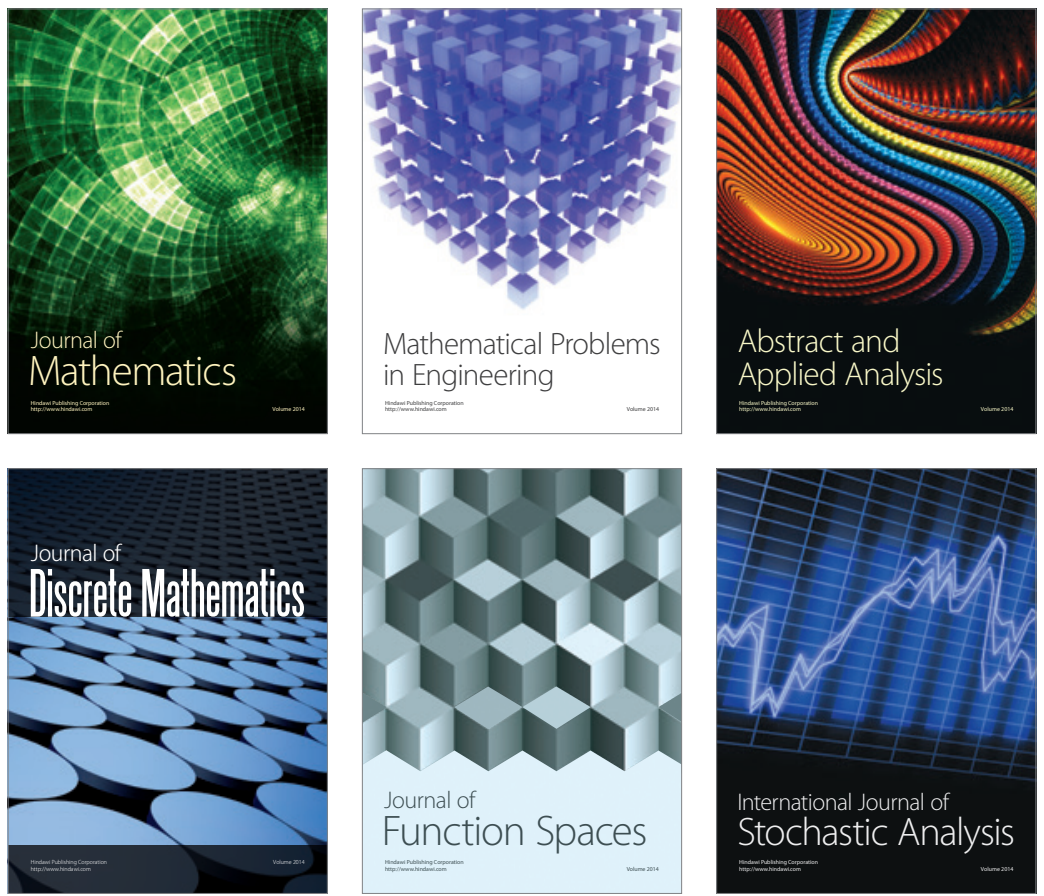

Journal of

Function Spaces

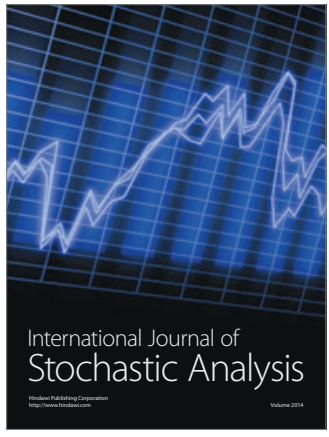

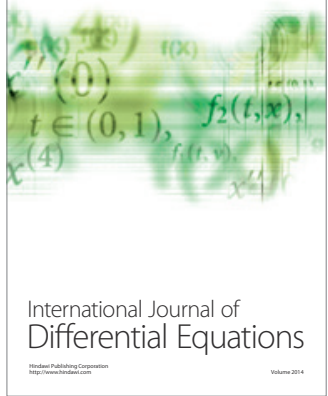
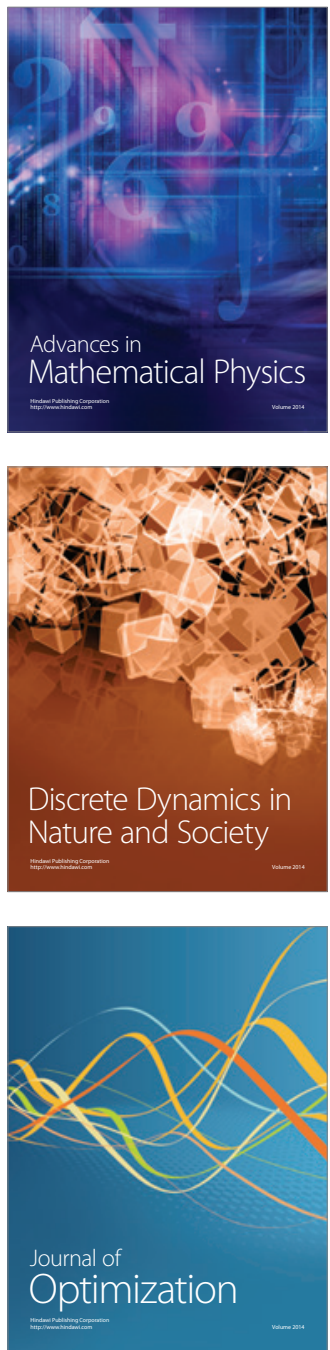